\title{
TERMS IN ELECTORAL LAW THROUGH THE PRISM OF THE CONCEPT OF BALANCE OF THE CONSTITUTIONAL REGULATION OF ELECTORAL RELATIONS
}

\author{
Ekaterina M. Yakimova \\ Baikal State University, Irkutsk, Russian Federation
}

Introduction: the concept of terms in electoral law is an established system of views on the procedural aspects of the implementation of electoral legal relations. However, certain aspects of electoral terms have been and will continue to be changed in order to improve the electoral process. The purpose of the work is to identify the substantial factors that influence the transformation of electoral terms. Methods: in the course of the research, both general scientific and special methods of cognition of social and legal phenomena (the formal legal method and the circular causality method) were used. Results: the reasons for the transformation of electoral terms under the influence of the implementation of the concept of balance of the constitutional regulation, which in this case has a transformative effect on the electoral legal relations, are revealed. Conclusions: the search for a balance between the need to form the public authorities and modern realities, which do not always allow for the effective organization of the electoral process, will be accompanied by the transformation of the legally established concept of electoral terms implemented in modern Russia.

Key words: elections, electoral law, electoral legal relations, balance, terms.

Citation. Yakimova E.M. Terms in Electoral Law Through the Prism of the Concept of Balance of the Constitutional Regulation of Electoral Relations. Legal Concept $=$ Pravovaya paradigma, 2020, vol. 19, no. 4, pp. 75-79. (in Russian). DOI: https://doi.org/10.15688/lc.jvolsu.2020.4.10

УДК 342.8

ББК 67.400 .5
Дата поступления статьи: 06.11.2020

Дата принятия статьи: 25.11.2020

\section{СРОКИ В ИЗБИРАТЕЛЬНОМ ПРАВЕ ЧЕРЕЗ ПРИЗМУ КОНЦЕПЦИИ РАВНОВЕСИЯ КОНСТИТУЦИОННОГО РЕГУЛИРОВАНИЯ ИЗБИРАТЕЛЬНЫХ ПРАВООТНОШЕНИЙ}

\author{
Екатерина Михайловна Якимова \\ Байкальский государственный университет, г. Иркутск, Российская Федерация
}

\begin{abstract}
Введение: концепция сроков в избирательным праве является сложившейся системой взглядов на процедурные аспекты реализации избирательных правоотношений. Вместе с тем отдельные проявления избирательных сроков подвергались и будут подвергаться изменениям в целях совершенствования избирательного процесса. Целью работы является выявление субстанциональных факторов, оказывающих воздействие на трансформацию избирательных сроков. Методы: в процессе исследования получили применение как общенаучные, так и специальные методы познания социально-правовых явлений (формально-юридический метод, метод круговой причинности). Результаты: выявлены причины трансформации избирательных сроков под влиянием реализации концепции равновесия конституционного регулирования, в данном случае имеющей преобразовательное воздействие на избирательные правоотношения. Выводы: поиски баланса между необходимостью формирования органов публичной власти и современными реалиями, не всегда позволяющими эффективно организовать избирательный процесс, будут сопровождаться трансформацией легально закрепленной концепции избирательных сроков, реализуемой в современной России.

Ключевые слова: выборы, избирательное право, избирательные правоотношения, равновесие, сроки.
\end{abstract}


Цитирование. Якимова Е. М. Сроки в избирательном праве через призму концепции равновесия конституционного регулирования избирательных правоотношений // Legal Concept = Правовая парадигма. 2020. - T. 19, № 4. - C. 75-79. - DOI: https://doi.org/10.15688/lc.jvolsu.2020.4.10

\section{Введение}

Выбор того или иного варианта правового регулирования различных видов правоотношений зависит от множества факторов. Стоит учитывать, что значительное влияние на композицию правового пространства оказывает достижение цели обеспечения равновесия внутри интаэросистемы [8] «человек - общество - государство» посредством обеспечения равновесия системы правового регулирования, под которым можно понимать комплекс воздействующих на общественную систему сходящихся сил с целью обеспечения устойчивого ее развития с использованием средств правового регулирования [12].

\section{Значение темпоральной составляющей избирательного процесса}

Значение сроков в избирательном праве не стоит недооценивать, поскольку в концепции сроков находит, как представляется, отражение вся избирательная система конкретного государства (в настоящей работе избирательная система понимается в широком смысле как система общественных отношений, связанных с формированием органов публичной власти, охватывающая вопросы определения круга избирателей и инфраструктуры выборов, отношений на каждой стадии избирательного процесса [4, с. 104]), дается ответ на вопрос о базовых установках организации и проведении выборов.

Анализу сроков в избирательном праве посвящены работы О.Ю. Евсеевой [1], В.В. Игнатенко [3], С.Д. Князева [5], Е.М. Коровина [6], С.Н. Слободчиковой [10] и других исследователей. Авторы признают важность сроков для всей избирательной системы, а не только избирательного процесса, с чем сложно не согласиться.

Избирательные сроки могут быть подвергнуты обобщению, однако следует учитывать, что они вписаны в избирательную систему конкретного государства, только совместное исследование сроков и иных способов поддержания равновесия правового регулирования избирательных правоотношений позволяет сделать достоверные выводы о том, как сроки влияют на избирательную систему и как избирательная система влияет на сроки.

Срок процессуальной деятельности является, помимо субъектного состава, цели и задач, действий, процессуальных документов, одной из субстанциональных характеристик стадии любого процесса. Несмотря на то что большинство сроков не являются пресекательными, они служат ориентиром для участников процесса и характеризуют значение процессуальных действий на конкретной стадии определенной правовой деятельности. Чрезмерная растянутость сроков вызывает снижение эффективности процессуальных действий конкретной стадии и процессуальной активности в целом, следовательно установление сроков стадий определенной деятельности и контроль за их соблюдением являются условием реализации целей такой деятельности. Для избирательного процесса соблюдение сроков особенно важно в связи с тем, что, если формирование органа публичной власти связано с проведением выборов, нарушение сроков вызовет невозможность обеспечения государственно-управленческой функции [9], а следовательно, нарушит равновесное состояние общественной и государственной системы.

Избирательный процесс за весь период использования выборов как способа формирования органа публичной власти, а также занятия отдельных публичных должностей эволюционировал. В полной мере данное утверждение относится и к выборам. Причиной тому стал технический прогресс (сокращение времени доставки бюллетеней по участкам, получение информации о результатах выборов с участков и их обобщение). Ярким примером являются выборы Президента США, когда технические ограничения сыграли значительную роль в использовании института выборщиков. В настоящее время данная проблема устранена, и неизмененность избирательной системы связана уже с иными факторами. 


\section{Избирательные сроки: трансформация и ее причины}

Продолжительность избирательной кампании на выборах в различные органы публичной власти или занятия отдельных публичных должностей может изменяться, что связано как с развитием информационных систем, формированием устоявшейся партийной системы, так и с трансформацией избирательной системы. К примеру, Федеральный закон от 17 мая 1995 г. № 76-Ф3 «О выборах Президента РФ» предусматривал срок избирательной кампании в 214 дней, а Федеральный закон от 10 января 2003 г. № 19-Ф3 «О выборах Президента РФ» - 90 дней; Федеральный закон от 21 июня 1995 г. № 90-Ф3 «О выборах депутатов Государственной Думы Федерального Собрания РФ» устанавливал срок кампании в 153 дня, Федеральный закон от 22 февраля 2014 г. № 20-Ф3 «О выборах депутатов Государственной Думы Федерального Собрания РФ» - 90 дней (расчет проведен Е.М. Коровиным, см.: [7, с. 215-216]). Причем не прослеживается тенденция постоянного сокращения срока избирательной кампании. Например, Федеральный закон от 31 декабря 1999 г. № 228-Ф3 «О выборах Президента РФ» в различных редакциях устанавливал разные сроки избирательной кампании: редакция 2003 г. 80 дней, 2004 г. - 94 дня, 2008 г. - 95 дней, 2012 г. - 100 дней, 2014 г. - 90 дней. Таким образом, примерно девяностодневный срок оказался равновесным, позволил сочетать различные функции избирательного процесса с оптимальными временными затратами.

Уменьшение сроков предвыборной агитации также является показателем того, что выборы приобретают технических характер, но это необязательно говорит о незаинтересованности граждан в процессе получения информации о кандидатах, а скорее, о достижении равновесия избирательной системы и готовности решать те же задачи за меньший срок с использованием более действенных сроков донесения информации до избирателей.

Среди факторов, способствующих трансформации избирательных сроков, стоит отметить и формирование партийных систем. В настоящее время короткие сроки избирательных кампаний (в Великобритании -
20 дней, в Японии - 12-17) свойственны преимущественно государствам с устоявшейся партийной системой, когда граждане сформировали свои политические убеждения или имеют четкое представление о программе основных претендентов на распределение мест в представительном органе или кандидате на замещение публичной должности. Появление на политической арене новых игроков, способных получить значительное для формирования сильной фракции число голосов (например, Шотландская националистическая партия в Великобритании), вносит коррективы в состав представительного органа, но не оказывает влияние на саму партийную, а вместе с ней избирательную систему.

В современной России проводится интересный эксперимент, наглядно показывающий, что изменение избирательных сроков может повлечь глубокую трансформацию всей избирательной системы: увеличение периода голосования с одного до нескольких дней привело к актуализации вопроса об изменении сроков предвыборной агитации.

В сентябре 2020 г. в Российской Федерации стадия голосования была увеличена до трех дней. Однозначную положительную оценку данному новшеству дать достаточно сложно, поскольку цель «разгрузить» воскресенье достигнута не была: избиратели преимущественно голосовали в воскресный день (например, в Иркутской области на досрочных выборах губернатора явка 11 сентября составила 8,1\%, 12 сентября - 7,89\%, 13 сентября - 16,61\% при итоговом показателе в $32,6 \%$, в Ленинградской области на досрочных выборах губернатора явка 11 сентября составила 15,45 \%, 12 сентября - 12,84\%, 13 сентября - 23,23 \% при итоговом показателе 51,52 \%, однако есть и исключения: в Еврейской автономной области на выборах губернатора явка 11 сентября составила $32,5 \%$, 12 сентября - 25,39\%, 13 сентября - 15,13\% при итоговом показателе в 73,02 \%) [2]. Кроме того, стоит учитывать, что усложнилась процедура обеспечения прозрачности выборов с точки зрения недопущения совершения противоправных деяний.

Изменение сроков голосования повлекло возникновение накладок на стадиях предвыборной агитации и голосования. Однако такое наложение позволило взглянуть по-другому на 


\section{ТЕОРИЯ И ПРАКТИКА ГОСУДАРСТВЕННО-ПРАВОВОГО РАЗВИТИЯ}

«день тишины» и перенести из научных дискуссий в сферу обсуждения законодателями и правоприменителями вопрос о его трансформации, который, как представляется, давно назрел.

Призывы скорректировать сроки предвыборной агитации давно высказываются юридическим сообществом. В частности, С.Н. Слободчикова утверждает: в соответствующем законодательстве следует указать, что агитационный период, предвыборная агитация «прекращается в ноль часов по местному времени дня, следующего за днем голосования» $[11$, с. 15$]$. В качестве обоснования исследователь отмечает, что современная реальность априори не позволяет «создать информационный вакуум. Большинство агитационных материалов сохраняются ко дню голосования и продолжают в определенной степени воздействовать на электоральный выбор. К примеру... листовки, плакаты и иные печатные агитационные материалы, размещенные на рекламных конструкциях или иных стабильно размещенных объектах, могут сохраняться в день голосования. В свою очередь, в условиях организации социальных взаимоотношений в сети Интернет вообще не представляется возможным остановить весь оборот агитационных материалов ко “дню тишины”. Следовательно, положения законодательных актов Российской Федерации, запрещающих предвыборную агитацию в указанный период, не реализуются и требуют внесения соответствующих изменений» [11, с. 124]. Из положений диссертационного исследования С.Н. Слободчиковой прослеживается мысль, что «день тишины» в полном объеме нецелесообразно отменять, поскольку его элементы в реальном мире способствуют поддержанию режима минимизации давления информационного поля на волю избирателей. Вместе с тем инициативы по проведению трехдневного голосования ставят вопрос об изменении подхода к необходимости соблюдения «дня тишины» и его существованию со стороны законодателя, поскольку голосование проводится в пятницу, когда «день тишины» еще не наступил.

\section{Выводы}

Таким образом, сроки в избирательном праве не произвольны, они дополняют изби- рательную систему и могут выступать фактором ее изменения (например, сокращение сроков избирательной кампании влечет за собой трансформацию работы партий с населением, что приводит к изменениям структуры самих партий). Стремление обеспечить сбалансированность избирательной системы является краеугольным камнем ее построения и функционирования, что реализуется и в установленных сроках осуществления процессуальных действий.

\section{СПИСОК ЛИТЕРАТУРЫ}

1. Евсеева, О. Ю. Сроки в избирательном праве Российской Федерации: автореф. дис. ... канд. юрид. наук: 12.00.02 / Евсеева Ольга Юрьевна. - М., 2012. -22 c.

2. Единый день голосования 13 сентября 2020 года // ЦИК Российской Федерации. - Электрон. текстовые дан. - Режим доступа: http:/cikrf.ru/analog/ ediny-den-golosovaniya-2020/kategorii-viborov/ (дата обращения: 05.11.2020). - Загл. с экрана.

3. Игнатенко, В. В. Электоральные сроки в механизме защиты избирательных прав граждан / В. В. Игнатенко // Академический юридический журнал. - 2020. - № 1 (79). - С. 62-66.

4. Избирательное право и избирательный процесс в Российской Федерации : учеб. для вузов / отв. ред. А. В. Иванченко. - М. : Норма, 1999. $-856 \mathrm{c}$.

5. Князев, С. Д. Российское избирательное право : учебник / С. Д. Князев. - Владивосток : Изд-во Дальневосточ. ун-та, 2001. - 448 с.

6. Коровин, Е. М. Порядок и сроки оспаривания итогов голосования и результатов выборов в контексте правовых позиций Конституционного Суда Российской Федерации / Е. М. Коровин // Конституционное и муниципальное право. - 2015. № 7. - C. $12-16$.

7. Коровин, Е. М. Электоральные сроки как условие реализации и защиты избирательных прав граждан в Российской Федерации : дис. ... канд. юрид. наук: 12.00.02 / Коровин Евгений Михайлович. - Владивосток, 2019. - 216 с.

8. Крылов, Ю. К. Интаэрология и синергетика / Ю. К. Крылов // Синергетика и методы науки / под ред. М. А. Васина. - СПб. : Наука, 1998.-С. 77-94.

9. Приходько, Т. В. Случаи ограничения прав и свобод человека и гражданина на примере России и Германии: сравнительно-правовой анализ / Т. В. Приходько // Сибирский юридический вестник. -2012. -№ 1. - С. 129-132. 
10. Слободчикова, С. Н. Правовая природа сроков в российском избирательном праве / С. Н. Слободчикова //Академический юридический журнал. - 2014. - № 3 (57). - С. 48-54.

11. Слободчикова, С. Н. Свободные выборы как избирательный стандарт (конституционно-правовое исследование) : дис. ... канд. юрид. наук: 12.00.02 / Слободчикова Светлана Николаевна. - Иркутск, 2019. - 219 с.

12. Якимова, Е. М. Концепция равновесия системы конституционного регулирования предпринимательской деятельности : монография / Е. М. Якимова. - М. : Юстицинформ, 2020. - 320 с.

\section{REFERENCES}

1. Evseeva O.Ju. Sroki v izbiratelnom prave Rossiyskoy Federatsii: avtoref. dis. ... kand. yurid. nauk: 12.00.02 [Terms in the Electoral Law of the Russian Federation. Cand. jurid. sci. abs. diss.]. Moscow, 2012. 22 p.

2. Edinyy den golosovaniya 13 sentyabrya 2020 goda [Single Voting Day September 13, 2020]. URL: http://cikrf.ru/analog/ediny-den-golosovaniya2020/kategorii-viborov/ (accessed 5 November 2020).

3. Ignatenko V.V. Jelektoralnye sroki V mekhanizme zashhity izbiratelnykh prav grazhdan [Electoral Terms in the Mechanism for Protecting the Electoral Rights of Citizens]. Akademicheskiy juridicheskiy zhurnal [Academic Law Journal], 2020, no. 1 (79), pp. 62-66.

4. Izbiratelnoe pravo i izbiratelnyy protsess $v$ Rossiyskoy Federatsii [Electoral Law and the Electoral Process in the Russian Federation: A Textbook for Universities]. Moscow, Norma Publ., 1999. 856 p.

5. Knjazev S.D. Rossiyskoei zbiratelnoe pravo [Russian Electoral Law]. Vladivostok, Far Eastern University Publishing house, 2001. 448 p.

6. Korovin E.M. Poryadok i sroki osparivaniya itogov golosovaniya i rezultatov vyborov v kontekste pravovykh pozitsiy Konstitutsionnogo Suda Rossiyskoy Federatsii [Procedure and Deadlines for Challenging the Results of Voting and Election Results in the Context of the Legal Positions of the Constitutional Court of the Russian Federation]. Konstitutsionnoe $i$ munitsipalnoe pravo [Constitutional and Municipal Law], 2015, no. 7,pp. 12-16.

7. Korovin E.M. Jelektoralnye sroki kak uslovie realizatsii $i$ zashchity izbiratelnykh prav grazhdan $v$ Rossiyskoy Federatsii: dis. ... kand. yurid. nauk: 12.00.02 [Electoral Deadlines as a Condition for the Realization and Protection of Eectoral Rights of Citizens in the Russian Federation. Cand. jurid. sci. diss.]. Vladivostok, 2019.216 p.

8. Krylov Ju.K. Intaerologiya i sinergetika [Intaerology and Synergy]. Sinergetika $i$ metody nauki [Synergy and Methodology of Science]. SanktPeterburg, Nauka Publ., 1998, pp. 77-94.

9. Prikhodko T.V. Sluchai ogranicheniya prav i svobod cheloveka i grazhdanina na primere Rossii i Germanii: sravnitelno-pravovoy analiz [Cases of Restriction of Human and Civil Rights and Freedoms on the Example of Russia and Germany: Comparative Legal Analysis]. Sibirskiy yuridicheskiy vestnik [Siberian Law Bulletin], 2012, no. 1, pp. 129-132.

10. Slobodchikova S.N. Pravovaya priroda srokov v rossiyskom izbiratelnom prave [The Legal Nature of Deadlines in Russian Electoral Law]. Akademicheskiy yuridicheskiy zhurnal [Academic Law Journal], 2014, no. 3 (57), pp. 48-54.

11. Slobodchikova S.N. Svobodnye vybory kak izbiratelnyy standart (konstitutsionno-pravovoe issledovanie): dis. ... kand. yurid. nauk: 12.00.02 [Free Elections as an Electoral Standard (Constitutional and Legal Study). Cand. jurid. sci. diss.]. Irkutsk, 2019.219 p.

12. Jakimova E.M. Kontseptsiya ravnovesiya sistemy konstitutsionnogo regulirovaniya predprinimatelskoy deyatelnosti [Concept of the Equilibrium of the System of Constitutional Regulation of Entrepreneurial Activity]. Moscow, Justicinform Publ., 2020.320 p.

\section{Information About the Author}

Ekaterina M. Yakimova, Candidate of Sciences (Jurisprudence), Associate Professor, Department of Legal Support of National Security, Baikal State University, Lenina St, 11, 664003 Irkutsk, Russian Federation, yakimova_katerin@mail.ru, https://orcid.org/0000-0002-2951-4131

\section{Информация об авторе}

Екатерина Михайловна Якимова, кандидат юридических наук, доцент, доцент кафедры правового обеспечения национальной безопасности, Байкальский государственный университет, ул. Ленина, 11, 664003 г. Иркутск, Российская Федерация, yakimova_katerin@mail.ru, https://orcid.org/0000-0002-2951-4131 